\title{
"LA AUTOEVALUACIÓN EN LAS PRÁCTICAS PEDAGÓGICAS DE LOS ALUMNOS DEL PROFESORADO EN ENSEÑANZA PRIMARIA"
}

\author{
Marta Herrera \\ Facultad de Ciencias de la Educación \\ Universidad Nacional de Comahue, Argentina
}

\section{Presentación}

La evaluación es y ha constituido un tema de preocupación en nuestro accionar, ya sea como docentes o como investigadores. Como docentes, porque el período de formación de los futuros maestros se encuentra permeado por esta problemática, sobre todo en la cátedra "Residencia", ubicada en el tramo final de la carrera. Como investigadores, porque pertenecemos a un equipo de investigación que desde hace varios años se aboca al tratamiento de este tema. En la actualidad, con un proyecto denominado "La escritura del docente en la evaluación", que tiene como finalidad explicitar el valor didáctico de las correcciones y señalamientos que los docentes realizan en las producciones escritas por los alumnos de Nivel Medio del Área de Ciencias Sociales.

La información pretende dar cuenta de los procesos de atoevaluación de las prácticas de residencia que llevan a cabo los alumnos del Profesorado en Enseñanza Primaria de la Facultad de Ciencias de la Educación, Universidad Nacional del Comahue, República Argentina. Dicha información está organizada en tres apartados. En el primero se describe la propuesta de Residencia, que da cuenta de las articulaciones entre la teoría y la práctica como así también los propósitos que direccionan nuestro trabajo. En el segundo, se presentan las consideraciones teóricas acerca de la evaluación y de la autoevaluación. En el último apartado, se sintetizan los procesos vividos por los alumnos residentes y a modo de reflexión, se presentan algunas consideraciones que permiten seguir avanzando en el conocimiento de los procesos evaluativos.

\section{Aspectos descriptivos de la propuesta}

El Plan de Estudios del Profesorado en Enseñanza Primaria está estructurado en asignaturas y talleres, que reciben el nombre de Lectura de la Práctica Docente. Son tres en total y contemplan la gradual inserción de los estudiantes en las instituciones escolares, intentando un trabajo de análisis y reflexión que vincule las prácticas docentes cotidianas con los aportes teóricos que van proporcionando las otras asignaturas. La cátedra "Residencia" marca la culminación de esa línea curricular. En esta cátedra, partimos de considerar que si se adhiere a una modalidad constructiva e interactiva en la relación docente - alumno, es necesario adoptar una modalidad semejante en la formación docente. Al mismo tiempo, si se reconocen en el alumno aproximaciones sucesivas al objeto de conocimiento es necesario también reconocer que la formación del futuro docente es otra construcción que, como tal, presenta momentos de conflicto, aparente quietud, saltos cualitativos, reorganizaciones y coordinaciones, es decir, toda la complejidad de un proceso de aprendizaje. En ese complejo proceso, las prácticas evaluativas de nuestros/as alumnos/as residentes suelen ser el resultado de un profundo análisis y reflexión por parte de ellas.

Los alumnos, de a dos, inician sus prácticas en distintos establecimientos de enseñanza primaria en la ciudad de Cipolletti, provincia de Río Negro, Argentina. A partir de ese momento, comienza la primera etapa del trabajo entre profesores y practicantes, referida concretamente a la 
situación particular de cada pareja en la escuela: presentación al cuerpo directivo y docente, charlas con el docente del grado con el fin de informarle sobre las características de la residencia.

Durante las primeras semanas, se recaban datos sobre el establecimiento y su contexto socio - histórico para luego analizar la institución en la que van a realizar sus prácticas sobre la base de la información obtenida a través de diferentes fuentes: entrevistas a docentes, directivos, alumnos, padres, encuestas a la comunidad, lectura y descripción del Libro histórico y del Proyecto Institucional...

Una vez terminada esta etapa, se inician las observaciones de clases, tratando de centrarse tanto en el docente, como en el grupo de alumnos, con el fin de conocer las características generales del grado y contar con datos empíricos para la propuesta didáctica a llevar a cabo durante la residencia.

Las primeras clases se acuerdan con el docente, quien les proporciona los temas de las distintas áreas. Las planificaciones respectivas deben ser aprobadas tanto por el docente como por el profesor y recién entonces, los alumnos están en condiciones de "pararse" frente al curso. Estas primeras prácticas, sujetas a reformulaciones y ajustes, constituyen un verdadero proceso de aprendizaje, con avances y retrocesos, donde los alumnos practicantes, llevan a cabo un paulatino acercamiento a la práctica pedagógica. Una vez aprobada esta etapa, los alumnos están en condiciones de "residir" en el grado. La docente les proporciona los contenidos de cada área, y cada uno de ellos debe seleccionar y secuenciar los mismos a partir de una propuesta didáctica que priorice la construcción del conocimiento por parte del grupo de alumnos que tendrán a su cargo. Dicha propuesta debe ser presentada a la cátedra para su consideración y aprobación. Una vez aprobada, cada integrante de la pareja permanece, durante tres semanas, al frente del dictado de clases en todas las áreas, desempeñando además, aquellas tareas inherentes al quehacer docente, como son registrar la asistencia, recibir y despedir a los alumnos, encargarse de los recreos, tocar el timbre de entrada y salida al establecimiento, servir la copa de leche, brindar los primeros auxilios, etc.

Finalizada esta etapa, los alumnos presentan, por escrito, un informe que dará cuenta de la práctica realizada, intentando comprender e interpretar los propios procesos vividos.

\section{Consideraciones teóricas}

El término evaluación encierra múltiples significados, al respecto, Bertoni y otros (1995) señalan que, en primer lugar, evaluar parece involucrar el hecho de medir con precisión y expresa una medida cuantificada; en segundo lugar, evaluar implica operaciones como estimar, apreciar, aprehender, pero también pronunciar un juicio cualitativo y aproximativo sobre una realidad.

Por su parte, Félix Angulo Rasco (1994: 285) efectúa una distinción entre los conceptos de evaluación y de "assessment", ligando la primera a "una acepción amplia que correspondería al proceso por el cual conocemos y valoramos la calidad del servicio y el papel de los distintos componentes en el mismo". Mientras que "assessment", queda vinculado "a una acepción estrecha (o reducida) que señalaría al proceso o procedimiento por el que averiguamos su "calidad" únicamente a través de la repercusión de dicho servicio en individuos o grupos".

Esto da cuenta de que, desde la polisemia del término, la evaluación es una actividad compleja. Evaluar es una acción que involucra a los principales actores del acto didáctico y pone en 
evidencia la concepción subyacente en las acciones evaluativas que despliega el docente. En consecuencia, la evaluación supone complejidad, porque es una decisión a tomar, es una iniciativa a poner en marcha, es una opción metodológica a tener en cuenta, es una transformación a considerar, es una estrategia a planificar.

El término complejidad, viene de complexus, que significa lo que está tejido en conjunto, haciendo alusión al reconocimiento necesario de un principio de "lo incompleto" y de incertidumbre.

En suma, es un entramado de constituyentes heterogéneos y asociados que presenta la paradoja de lo uno y lo múltiple. Esto implica una tensión permanente entre la aspiración de la totalidad del saber y el reconocimiento de "lo incompleto" de todo conocimiento. (Morín, 1995: 23)

El orden, el desorden, lo uno y lo diverso se complementan e interactúan en los procesos evaluativos porque, de alguna manera, estarían dando cuenta de una necesidad de organización, de una necesidad de encontrar los principios de evolución comunes de los fenómenos para tratar de explicarlos.

Pensar a la evaluación desde este lugar posibilitaría abordar los procesos y los resultados evaluativos desde las dimensiones genuinas de su constitución, a la vez que se reconocería la totalidad y las partes que conforman dichos procesos.

En este sentido, estaríamos reconociendo a la evaluación como un acto de conocimiento porque definiría, en la práctica, la coherencia entre los postulados y las acciones. Entre lo que se dice y lo que se hace, entre lo deseable y lo posible. No todo debe ser evaluado, pero sí debemos tomar conciencia de nuestras elecciones en el acto de evaluar.

Entender la complejidad de la enseñanza implica reconocer que el conocimiento adquirido debe convertirse en un instrumento de actuación e indagación sobre la realidad, ya no se trata de un saber dogmático, sino de un saber que se enriquece, que se construye a partir de las contradicciones y conflictos en un sentido psíquico y social.

Por tanto, la actividad de evaluar se convierte en valorativa y, como tal, el sujeto que evalúa y el sujeto evaluado están directamente implicados y comprometidos "con una actividad que debe orientarse por principios de justicia" (Alvarez Méndez, 2000: 133)

La evaluación, parte esencial del proceso de enseñar y de aprender, es una etapa de síntesis y replanteo para guiar toda la acción docente. Desde aquí, se la concibe como una responsabilidad pedagógica, ética y social, y no como una mera tarea técnica de control, selección y promoción. También debe estar orientada a que los alumnos se apropien progresivamente de los criterios de evaluación, que desarrollen y afinen la práctica de la autoevaluación, el análisis y la corrección de los propios errores.

La autoevaluación en esta instancia de prácticas surge como un proyecto propio del alumno residente, donde cada uno decide las acciones que le permiten tomar distancia de la práctica para trabajar sobre ella, objetivarla y observar las propias posibilidades y limitaciones y desde allí poder ver lo que en la acción cotidiana es imperceptible.

"La autoevaluación así concebida debe tener - como mínimo - dos condiciones básicas: una relacionada con la capacidad de objetivar las acciones realizadas, y la otra ligada a la responsabilidad y al compromiso" (Palou, 1998: 113)

En este sentido, la autoevaluación permite un proceso reflexivo útil para el análisis de las acciones realizadas, de acuerdo con el proyecto en el que se inscriben. 
Los modos de pensar, las formas de comprender la vida, los valores implícitos son diferentes en cada sujeto. Cada uno responde a una cosmovisión en la que inciden su pertenencia social y su peculiar historia de vida. La profesionalización implica no sólo el dominio de la disciplina, sino la toma de conciencia de las propias contradicciones que enmarcan su práctica diaria. Al decir contradicciones se hace referencia a la inconsistencia, al quiebre, al espacio de fractura entre lo pensado, lo dicho y lo actuado.

Es por ello que el profesor evaluador, en el caso que nos ocupa, debe re - definir su propia función y orientar sus acciones a la coparticipación, a la deliberación y a la innovación, para que el alumno evaluado "cuente con" las correspondientes explicaciones. Ese "contar con" permite una nueva construcción evaluativa que evita las prácticas arbitrarias en las que sólo actúa quien ostenta el poder y tiene la última palabra.

La posibilidad de diálogo se constituye en la fuente fundamental para obtener información útil sobre los procesos evaluativos, porque presta atención a la comprensión e interpretación de aspectos puntuales tal como se van desarrollando en un aquí y en un ahora.

La autoevaluación es una forma de evaluación compartida entre el profesor y el alumno, donde el esfuerzo concertado entre las partes, se erige como garante de la más clara objetividad.

Por su parte, la observación y el contacto directo con el sujeto que se está evaluando contribuyen a que los juicios vertidos posean una base natural de veracidad y de justicia.

"En el momento de la evaluación, además del profesor - evaluador, el sujeto -evaluado tiene algo que decir, y lo dice participando directamente en el proceso de evaluar" (Alvarez Méndez, 2000: 136)

Para el profesor, el evaluar con justicia se convierte en una preocupación que tiene que ver con una dimensión ética. En esa preocupación, la pretensión de eficacia y la discusión técnica sobre los sentidos y significados de la práctica de los alumnos, cobran especial relevancia con la finalidad de emitir juicios objetivos en relación con el desempeño de cada uno de ellos. Desde ese lugar, el carácter cualitativo de la evaluación trasciende las técnicas y los recursos, porque lleva a la valoración y emisión de un juicio fundamentado, basado en la calidad de los datos obtenidos.

\section{Los procesos vividos por los alumnos}

Los procesos vividos por los alumnos se visualizan en los informes finales que ellos presentan al término de la "Residencia" y, para dar cuenta de ello, hemos tomado párrafos de dos de ellos, con la autorización de sus autores.

Los alumnos residentes ingresan a la institución escolar para iniciar un complejo camino de "Iniciación a la Docencia" que Gloria Edelstein (1995: 37) define como “... un acto novedoso de inserción en un universo de práctica extraño hasta esta experiencia".

Esa extrañeza ante una escuela concreta, docentes concretos y alumnos concretos, provoca incertidumbre, como así también al llegar al grado, al docente y al grupo de alumnos con los cuales tendrán que realizar las prácticas. En esos momentos, acuden a sus conocimientos previos, a la teoría adquirida en los procesos de formación para resignificar los datos obtenidos y otorgarles una valoración que les sea útil para una interpretación posterior:

"En todo este proceso de conocimiento de los chicos somos conscientes que jugaron dos aspectos: tanto la formación académica recibida, especialmente en las materias 
de Psicología del Niño y Seminario de Psicología del Aprendizaje, como nuestra formación personal en lo que hace a nuestra relación con chicos." (Informe 2, pág. 5)

"Parados frente al grado, una vez más nos invadió el miedo, mezclado con la ansiedad de querer saber quiénes eran y qué esperaban de nosotros." (Informe 1, pág. 9)

"Con relación a los conocimientos con los que llegamos a la institución creemos que básicamente sabiamos el qué y el para qué enseñar, pero nuestra mayor incertidumbre se presentaba en el cómo hacerlo" (Informe 2, pág. 1)

Esta genuina preocupación por el cómo enseñar, da cuenta de la inseguridad que portan con respecto a la posesión y conocimiento de las técnicas como si el método por sí sólo les asegurara las certezas y los buenos resultados.

En las prácticas educativas, la clase es el escenario natural donde se despliegan las relaciones que dan sentido a una parte de la vida escolar. Allí, sujetos concretos en permanente interacción producen intercambio de significados en torno a saberes que connotan la relación entre el docente, el alumno y el conocimiento. En este marco, la profesionalización de la actividad docente implica la reflexión respecto de los supuestos que orientan su tarea, es decir, detenerse a pensar qué se hace, cómo se hace, para qué se hace. (Litwin y otros, 1999)

Aparece entonces el quehacer docente, ya sea en el docente observado, ya sea en sus propias prácticas:

"El conocimiento del maestro es una especie de "sentido práctico", es

decir, es un conocimiento útil, ya que existe en la práctica y para

resolver problemas prácticos" (Informe 1, pág. 11)

"A lo largo de esta etapa aprendimos que el interés, el entusiasmo y la

valoración que manifieste el docente por lo que enseña, será transmitido

al alumno y se constituirá en un factor motivador para el aprendizaje"

(Informe 1, pág. 15)

"Durante nuestras prácticas, no sólo nosotros fuimos maestros sino también nuestros chicos, innumerables veces ocuparon nuestro lugar.

Así a ellos les tocó enseñar y a nosotros aprender. Los chicos nos marcaron los tiempos y el ritmo de lo cotidiano, sin dejar que éste se vuelva rutina. Nos enseñaron que esperar no significa atrasarnos sino tomarnos un tiempo para respirar."(Informe 1, pág. 17)

Los alumnos residentes marcan una fuerte preocupación por el contenido, en función de la marcha de la enseñanza y de una adecuada articulación con los procesos de aprendizaje de los alumnos:

"En nuestras prácticas hay dos aspectos a tener en cuenta: por un lado está nuestra intencionalidad, es decir, qué queremos enseñar y para qué y por otro lado lo que el alumno siente como interesante... buscar un equilibrio entre lo que Porland llama "conocimiento escolar deseable" (lo que el docente interpreta como conveniente) y el interés del alumno. 
Para que esto sea así, es fundamental que haya una planificación flexible y que permita la improvisación ante la aparición de emergentes concretos." (Informe 1, pág. 5)

"... los contenidos que se dieron fueron trabajados en profundidad... De esta manera creemos que nuestra formación en lo que respecta a las diferentes didácticas nos ha proporcionado las herramientas mínimas y necesarias para desempeñarnos satisfactoriamente dentro del aula, sabiendo que queda mucho por aprender" (Informe 2, pág.3)

Tampoco desconocen que en la complejidad de la evaluación de la enseñanza se ponen en juego mecanismos mediadores con fuertes implicaciones personales como ocurre con la afectividad en el trato con los sujetos involucrados en esa relación:

"En cuanto a nuestra relación con la maestra, desde el principio se pudo establecer un vínculo afectivo y profesional que correspondió a las expectativas que teníamos, la de ser una guía, compañera y sobre todas las cosas "ser un mediador entre los alumnos - contenido - practicante dentro y fuera del contexto del aula" (Informe 1. Pág. 4) "A través de tener un contacto directo con los chicos, fuimos ampliando nuestros conocimientos respecto a cada uno de ellos, no sólo desde el aspecto cognoscitivo sino también desde lo afectivo" (Informe 2, pág.5)

El profesor de prácticas de Residencia también juega un papel importante en el proceso vivido por los dumnos. La observación y el contacto directo con los sujetos que se están evaluando contribuyen a que, a través del diálogo permanente, los juicios y opiniones vertidas posean una base natural de veracidad y de justicia. Desde una dimensión ética, preocupa evaluar con justicia y objetividad, porque como toda práctica social, la evaluación no es inmune al prejuicio y el error humano.
“...la relación mantenida con nuestra profesora de
residencia fue una relación de constante guía y apoyo, brindándonos
comentarios justos en los momentos adecuados, partiendo siempre desde
lo que a nosotras nos pasaba cerrando siempre las observaciones con
una reflexión, en ningún momento nos sentimos solas en nuestras
prácticas y muchas veces su tranquilidad en momentos de cierta
incertidumbre por parte nuestra en algunas situaciones, nos permitió
ganar confianza en nosotras mismas sabiendo que teníamos cierto
respaldo. Nos fueron de gran importancia las evaluaciones realizadas al
término de cada actividad a la que ella asistía" (Informe 2, pág. 3)

Por último, valorizan la posibilidad de comprender el proceso llevado a cabo, con sus limitaciones pero también con sus logros: 
“... sabemos que hemos cometido errores, sabemos que en ocasiones pudimos contradecirnos con nuestra postura, pero también no estamos ajenos de saber que la práctica es un proceso continuo, que se va constituyendo a través del análisis de la misma, preguntándonos sobre ella, buscando respuestas adecuadas y estrategias que respondan a las situaciones presentadas, para no quedarnos en el sentido común. Como diría un compañero:" ... prefiero dejar mi portafolio por la mitad y seguir cosechando aprendizajes" (Informe 1, pág. 7) "A modo de autoevaluación de nuestras prácticas, desde un principio nos propusimos e intentamos reflexionar en forma constante sobre la acción concreta" (Informe 2, pág. 6)

\section{A modo de reflexión}

El relato de esta experiencia, que año a año se repite con alumnos diferentes, con diferentes instituciones escolares y en contextos diferentes, permitió tomar distancia de la tarea y realizar algunas reflexiones con respecto al tema que nos ocupa.

La evaluación compartida, en esta instancia de Residencia, posibilita espacios de reflexión, análisis e interpretación de la propia práctica, tendientes a mejorar las acciones futuras. Si bien todo el peso de la tarea recae sobre los alumnos, el profesor de prácticas se encuentra inmerso en ese proceso con toda la responsabilidad que implica certificar saberes y prácticas de los futuros docentes.

La autoevaluación por parte de los alumnos no constituye sólo un requisito para la aprobación sino que conlleva una re - definición y consecuente replanteamiento de la función docente.

Por todo ello, debemos pensar la evaluación y la autoevaluación cualitativamente, porque significa poner el énfasis en la actitud, mentalidad y disposición para cuestionarnos hacia dónde estamos dirigiendo nuestros esfuerzos como docentes, a qué funciones y fines damos prioridad, en qué cosas ponemos nuestras energías y nuestro tiempo, que es también el tiempo de quienes con nosotros aprenden.

En palabras de un alumno:

"Hoy nos damos cuenta que sólo es cuestión de animarse a cruzar la muralla que separa la seguridad de la inseguridad" 


\section{BIBLIOGRAFIA}

ANGULO RASCO, F.: ¿A qué llamamos evaluación?: las distintas acepciones del término "evaluación" o por qué no todos los conceptos significan lo mismo en ANGULO RASCO, Félix y BLANCO, Nieves (Comp.): Teoría y desarrollo del Curriculum. Ediciones Aljibe, Málaga. (1994)

ALVAREZ MENDEZ, J. M.: Didáctica, curriculum y evaluación. Ensayos sobre cuestiones didácticas. Miño y Dávila Editores, Madrid. (2000)

BERTONI, A. y otros: Evaluación. Nuevos significados para una práctica compleja. Edit. Kapelusz, Buenos Aires. (1993)

EDELSTEIN, G. y CORIA, A.: Imágenes e Imaginación. Iniciación Iniciación a la Docencia. Kapelusz, Buenos Aires. (1995)

GIMENO SACRISTAN, J. y PEREZ GOMEZ, A.: Comprender y transformar la enseñanza. Morata, Madrid. (1992)

LITWIN, E.: La evaluación: campo de controversias y paradojas o un nuevo lugar para la buena enseñanza, en CAMILLONI y otros. Corrientes Didácticas Contemporáneas. Paidós, Buenos Aires. (1998)

LITWIN, E.; PALOU, C.; HERRERA, M.; PASTOR, L. y CALVET, M.: "La evaluación en la buena enseñanza", en Revista Ethos Educativo, Nro. 20. Instituto Michoacano de Ciencias de la Educación. México. (1999)

MERCADO, R. y ROCKWELL, E.: "La escuela, lugar de trabajo Docente", en Cuadernos de Educación. DIE, México. (1989)

MORIN, E.: Introducción al Pensamiento Complejo. Gedisa, Barcelona. (1995)

PALOU de MATE, M.: La evaluación de las prácticas docentes y la autoevaluación, en CAMILLONI y otros. Op. Cit. (1998)

PORLAN, R.: Constructivismo y escuela. Hacia un modelo deenseñanza aprendizaje basado en la investigación. Díada Edit. Sevilla. (1993) 